\title{
New Kinds of Global Domination In Fuzzy Graph Using Strong Arc - New Approach
}

\author{
G.K.Malathi ${ }^{1}$, C.Y. Ponnappan ${ }^{2}$ \\ ${ }^{1}$ Assistant Professor of Mathematics, Sri Meenakshi Government Arts College For Women (A), \\ Madurai-625002. \\ ${ }^{2}$ Assistant Professor, Department of Mathematics, Government Arts College, Melur 625106. \\ Tamilnadu, India. . \\ ${ }^{1}$ gkmalathisadasivam@gmail.com \\ ²pons_mdu1969@yahoo.com
}

Abstract : In this paper we establish the relation between strong arc domination number and global domination number ( new approach) of some standard graphs using strong arcs. Also various new kinds of global domination number of using strong arc is discussed.

Keywords : Fuzzy graph, Domination number, Strong arc, Non strong arc, Strong arc domination number, Fuzzy Global Domination number, Fuzzy semi perfect Global Domination number, Fuzzy Perfect Global Domination number.

AMS classification : $05 \mathrm{C} 72$

\section{Introduction.}

Fuzzy graph is the generalization of the ordinary graph. Therefore it is natural that though fuzzy graph inherits many properties similar to those of ordinary graph, it deviates at many places. The earliest idea of dominating sets date back to the origin of game of chess in India over 400 years ago in which placing the minimum number of chess piece (such as Queen, Knight etc.,) over chess board so as to dominate all the squares of chess board was investigated. The formal mathematical definition of domination was given by Ore.O in 1962. In 1975 A.Rosenfeld introduced the notion of fuzzy graph and several analogs of theoretic concepts such path, cycle and connected. A.Somasundaram and S.Somasundaram discussed the domination in fuzzy graph using effective arc. C.Y.Ponnappan and V.Senthil Kumar discussed the domination in fuzzy graph using strong arc. Before introducing new results in fuzzy graphs using strong arcs, we are placed few preliminary definitions and results for new one. 


\section{Preliminaries}

\section{Domination in Fuzzy Graph Using Strong Arc}

\section{Definition 2.1}

An $\operatorname{arc}(\mathrm{u}, \mathrm{v})$ of the fuzzy graph $\mathrm{G}(\sigma, \mu)$ is called a strong arc if $\mu(\mathrm{u}, \mathrm{v})=\mu^{\infty}(\mathrm{u}, \mathrm{v})$ else $\operatorname{arc}(\mathrm{u}, \mathrm{v})$ is called non strong. Strong neighborhood of $u \in V$ is $N_{S}(u)=\{v \epsilon V: \operatorname{arc}(u, v)$ is strong $\}$.

$\mathrm{N}_{\mathrm{S}}[\mathrm{u}]=\mathrm{N}_{\mathrm{S}}(\mathrm{u}) \mathrm{U}\{\mathrm{u}\}$ is the closed neighborhood of $\mathrm{u}$. The minimum cardinality of strong neighborhood $\delta_{\mathrm{S}}(\mathrm{G})=\min \left\{\left|\mathrm{N}_{\mathrm{S}}(\mathrm{u})\right|: \mathrm{u} \in \mathrm{V}(\mathrm{G})\right\}$. Maximum cardinality of strong neighborhood $\Delta_{\mathrm{S}}(\mathrm{G})=\max \left\{\left|\mathrm{N}_{\mathrm{S}}(\mathrm{u})\right|: \mathrm{u} \in \mathrm{V}(\mathrm{G})\right\}$.

\section{Definition 2.2}

Let $\mathrm{G}(\sigma, \mu)$ be a fuzzy graph. Let $\mathrm{u}, \mathrm{v}$ be two nodes of $\mathrm{G}(\sigma, \mu)$. We say that $\mathrm{u}$ dominates $\mathrm{v}$ if edge $(\mathrm{u}, \mathrm{v})$ is a strong arc. A subset $\mathrm{D}$ of $\mathrm{V}$ is called a dominating set of $\mathrm{G}(\sigma, \mu)$ if for every $\mathrm{v} \in \mathrm{V}-\mathrm{D}$, there exists $u \in D$ such that $u$ dominates $v$. A dominating set $\mathrm{D}$ is called a minimal dominating set if no proper subset of $\mathrm{D}$ is a dominating set. The minimum fuzzy cardinality taken over all dominating sets of a graph $\mathrm{G}$ is called the strong arc dominating number and is denoted by $\gamma_{\mathrm{s}}(\mathrm{G})$ and the corresponding set is called minimum strong arc dominating set. The number of elements in the minimum strong arc dominating set is denoted by $\mathrm{n}\left[\gamma_{\mathrm{s}}(\mathrm{G})\right]$.

\section{Global Domination in Fuzzy Graph Using Strong Arc}

\section{Definition 3.1}

Let $\mathrm{G}(\sigma, \mu)$ be a fuzzy graph. Let $\mathrm{u}, \mathrm{v}$ be two nodes of $\mathrm{G}(\sigma, \mu)$. We say that $\mathrm{u}$ dominates $\mathrm{v}$ if edge $(\mathrm{u}, \mathrm{v})$ is a strong arc. A subset $\mathrm{D}$ of $\mathrm{V}$ is called a dominating set of $\mathrm{G}(\sigma, \mu)$ if for every $\mathrm{v} \in \mathrm{V}-\mathrm{D}$, there exists $\mathrm{u} \in \mathrm{D}$ such that $\mathrm{u}$ dominates $\mathrm{v}$. A dominating set $\mathrm{D}$ is called a minimal dominating set if no proper subset of $\mathrm{D}$ is a dominating set. The minimum fuzzy cardinality taken over all dominating sets of a graph $\mathrm{G}$ is called the strong arc dominating number and is denoted by $\gamma_{\mathrm{s}}(\mathrm{G})$ and the corresponding set is called minimum strong arc dominating set. The number of elements in the minimum strong arc dominating set is denoted by $\mathrm{n}\left[\gamma_{\mathrm{s}}(\mathrm{G})\right]$.

The minimum fuzzy cardinality taken over all dominating sets of a graph $\bar{G}$, where $\bar{G}$ is the complement of the fuzzy graph $\mathrm{G}$, is called the strong arc dominating number of $\bar{G}$ and is denoted by $\gamma_{\mathrm{s}}(\bar{G})$ and the corresponding set is called the minimum strong arc dominating set of $\bar{G}$. The number of elements in the minimum strong arc dominating set is denoted by $\mathrm{n}\left[\gamma_{\mathrm{s}}(\bar{G})\right]$.

Fuzzy Global Dominating set using strong arc is the set which is the corresponding dominating set of $\min \left\{\gamma_{\mathrm{s}}(\mathrm{G}), \gamma_{\mathrm{s}}(\bar{G})\right\}$ and is denoted by $\gamma_{\mathrm{gs}}(\mathrm{G})$. The number of elements of fuzzy global dominating set using strong is denoted by $\mathrm{n}\left[\gamma_{\mathrm{gs}}(\mathrm{G})\right]$.

Note: Here we consider the fuzzy graphs with non effective edges.

\section{Definition 3.2}


If $\mathrm{n}\left[\gamma_{\mathrm{s}}(\mathrm{G})\right]=\mathrm{n}\left[\gamma_{\mathrm{s}}(\bar{G})\right]$ and $\mathrm{G}$ and $\bar{G}$ have different dominating sets then the domination is called Semi Perfect Fuzzy Global Domination using strong arc and the cardinality of the corresponding dominating set is denoted by $\gamma_{\mathrm{spgs}}(\mathrm{G})$.

\section{Definition 3.3}

If the minimum dominating set $\mathrm{D}$ of $\mathrm{G}$ which is the dominating set of both $\mathrm{G}$ and $\bar{G}$ using strong arc is called Fuzzy Perfect Global Dominating Set of G using strong arc and the cardinality of $\mathrm{D}$ is denoted by $\gamma_{\mathrm{pgs}}(\mathrm{G})$.

\section{Fuzzy Global Neighborhood Clique Domination Number Using Strong Arc.}

\section{Definition 4.1}

Let $\mathrm{G}$ be a fuzzy graph without isolated vertices and all arcs as strong arcs. A subset $D_{\text {ncs }}(G)$ of V is said to be a fuzzy neighborhood clique dominating set using strong arc if $\left\langle\mathrm{N}\left(\mathrm{D}_{\text {ncs }}(\mathrm{G})\right\rangle\right.$ is complete* provided $\mathrm{N}\left(\mathrm{D}_{\text {ncs }}(G)\right)$ contains the fuzzy vertices other than $\mathrm{D}_{\text {ncs }}(G)$. The fuzzy neighborhood clique domination number $\gamma_{\mathrm{ncs}}(\mathrm{G})$ is the minimum fuzzy cardinality taken over all minimal neighborhood clique dominating sets of G. Similarly $\mathrm{D}_{\text {ncs }}(\bar{G})$ of $\mathrm{V}$ is the fuzzy neighborhood clique dominating set of $\bar{G}$ using strong arc and $\gamma_{\mathrm{ncs}}(\bar{G})$ is the fuzzy neighborhood clique domination number of $\bar{G}$ using strong arc. Then the fuzzy global neighborhood clique dominating number using strong $\operatorname{arc} \gamma_{\text {gncs }}(G)$ is the minimum of $\gamma_{\mathrm{ncs}}(\mathrm{G})$ and $\gamma_{\mathrm{ncs}}(\bar{G})$. (ie) $\gamma_{\mathrm{gncs}}(\mathrm{G})=\min \left\{\gamma_{\mathrm{ncs}}(\mathrm{G}), \gamma_{\mathrm{ncs}}(\bar{G})\right\}$.

The set corresponding to $\min \left\{\gamma_{\mathrm{ncs}}(\mathrm{G}), \gamma_{\mathrm{ncs}}(\bar{G})\right\}$ is called as fuzzy global neighborhood clique dominating set using strong arc and is denoted by $\mathrm{D}_{\text {gncs }}(\mathrm{G})$.

* In complete graphs every vertex is adjacent with every other vertex and none of the edge is an effective edge.

Note : If $\gamma_{\mathrm{ncs}}(\mathrm{G})=\gamma_{\mathrm{ncs}}(\bar{G})$, then $\mathrm{D}_{\text {gncs }}(\mathrm{G})=\mathrm{D}_{\mathrm{ncs}}(\mathrm{G})$ and $\left\langle\mathrm{N}\left(\mathrm{D}_{\mathrm{ncs}}(\bar{G})\right\rangle\right.$ is complete not necessarily with all arcs as strong arcs.

\section{Example :4.2}

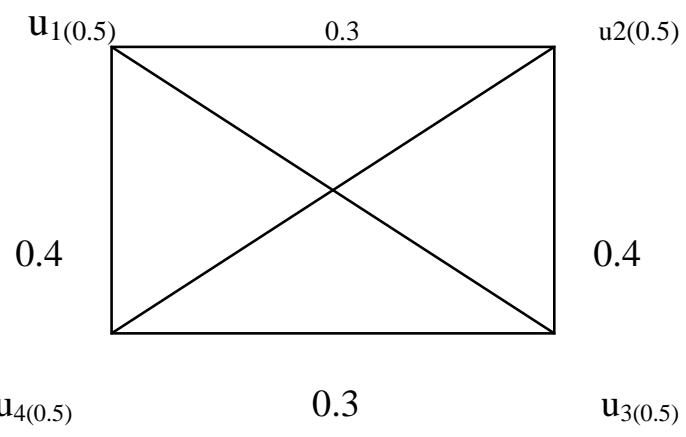

Here $\mu\left(\mathrm{u}_{1}, \mathrm{u}_{2}\right)=0.3$ and

$\mu\left(\mathrm{u}_{2}, \mathrm{u}_{4}\right)=0.3$

(G) -Figure 1(a)

$D_{\text {ncs }}(G)=\left\{u_{1}\right\} . \therefore \gamma_{\text {ncs }}(G)=0.5 .<N\left(D_{\text {ncs }}(G)>=\left\{\mathrm{u}_{2}, \mathrm{u}_{3}, \mathrm{u}_{4}\right\}\right.$ is complete. 


\section{2}

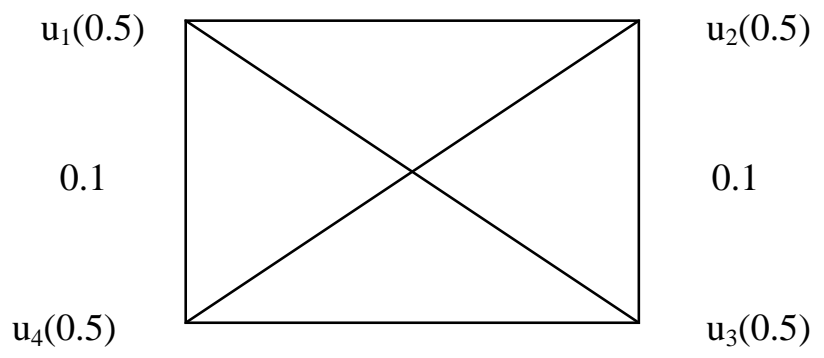

0.2

\section{$(\bar{G})$ - Figure 1(b)}

In $\bar{G}$ the $\operatorname{arcs}\left(\mathrm{u}_{1}, \mathrm{u}_{4}\right)$ and $\left(\mathrm{u}_{2}, \mathrm{u}_{3}\right)$ are non strong arcs. $\mu\left(\mathrm{u}_{1}, \mathrm{u}_{3}\right)=0.2$ and $\mu\left(\mathrm{u}_{2}, \mathrm{u}_{4}\right)=0.2$.

$$
\mathrm{D}_{\text {ncs }}(\bar{G})=\left\{\mathrm{u}_{1}, \mathrm{u}_{2}\right\} .<\mathrm{N}\left(\mathrm{D}_{\text {ncs }}(\bar{G})>=\left\{\mathrm{u}_{3}, \mathrm{u}_{4}\right\} \text { is complete. } \therefore \gamma_{\mathrm{ncs}}(\bar{G})=1 . \therefore \gamma_{\mathrm{gncs}}(\mathrm{G})=0.5\right.
$$

\section{Theorem 4.3}

If a fuzzy graph $\mathrm{G}$ is complete with all arcs as strong arcs and $\sigma\left(v_{i}\right)=c$, for all $v_{i}$ in $V$ then $\gamma_{n c s}(G)=c$.

\section{Proof :}

Let $\mathrm{G}$ be a complete fuzzy graph with vertex set $\left\{\mathrm{v}_{1}, \mathrm{v}_{2}, \ldots . \mathrm{v}_{\mathrm{i}-1}, \mathrm{v}_{\mathrm{i}}, \mathrm{v}_{\mathrm{i}+1}, \ldots \mathrm{v}_{\mathrm{n}}\right\}$. By definition of fuzzy complete graph , each $v_{i}$ dominates the other vertices. Let $D_{\text {ncs }}(G)$ be the neighborhood clique dominating set of $G$ using strong arcs. $D_{\text {ncs }}(G)=\left\{\mathrm{v}_{\mathrm{i}}: \sigma\left(\mathrm{v}_{\mathrm{i}}\right)=\mathrm{c}\right\} . \therefore \mathrm{N}\left(\mathrm{D}_{\mathrm{ncs}}(\mathrm{G})\right)=\left\{\mathrm{v}_{1}, \mathrm{v}_{2}, \ldots . \mathrm{v}_{\mathrm{i}-1}, \mathrm{v}_{\mathrm{i}+1}, \ldots \mathrm{v}_{\mathrm{n}}\right\}$ and $\mathrm{N}\left(\mathrm{D}_{\text {ncs }}(\mathrm{G})\right)>$ is complete. Since $\sigma\left(\mathrm{v}_{\mathrm{i}}\right)=\mathrm{c} \forall \mathrm{i}$, the fuzzy neighborhood clique domination number using strong arc is $\gamma_{\mathrm{ncs}}(\mathrm{G})=\sigma\left(\mathrm{v}_{\mathrm{i}}\right)=\mathrm{c}$.

\section{Theorem 4.4}

If $\mathrm{G}$ is a strong complete fuzzy graph with all arcs as strong arcs and $\sigma\left(\mathrm{v}_{\mathrm{i}}\right)=\mathrm{c}$, for all $\mathrm{v}_{\mathrm{i}}$ in $\mathrm{V}$ then $\gamma_{\mathrm{gncs}}(\mathrm{G})=\mathrm{c}$.

\section{Proof:}

Let $\mathrm{G}$ be a strong complete fuzzy graph with $\sigma\left(\mathrm{v}_{\mathrm{i}}\right)=\mathrm{c} . \therefore$ Every vertex of $\mathrm{G}$ is adjacent to every other vertex vertex of $\mathrm{G}$ and every arc is a strong arc. By previous theorem, $\gamma_{\mathrm{ncs}}(\mathrm{G})=\mathrm{c}$. Also $\gamma_{\mathrm{ncs}}(\bar{G}) \geq \mathrm{c} . \therefore$ $\gamma_{\text {gncs }}(G)=\mathrm{c}$.

\section{Theorem 4.5}

If $G$ is a strong complete fuzzy graph and $D_{n c s}(G)$ is the fuzzy neighborhood clique dominating set of $G$, then $\left\langle V-D_{\text {ncs }}(G)\right\rangle$ is also a strong complete fuzzy graph.

\section{Proof:}

Let $\mathrm{G}$ be a strong complete fuzzy graph with vertex set $\mathrm{V}=\left\{\mathrm{v}_{1}, \mathrm{v}_{2}, \ldots \mathrm{v}_{\mathrm{i}-1}, \mathrm{v}_{\mathrm{i}}, \mathrm{v}_{\mathrm{i}+1}, \ldots \mathrm{v}_{\mathrm{n}}\right\}$. By definition of strong complete fuzzy graph each $v_{i}$ dominates the other vertices in $\mathrm{G}$. The fuzzy neighborhood clique 
dominating set using strong arc $D_{\text {ncs }}(G)=\left\{v_{i} / v_{i}\right.$ is the vertex of minimum fuzzy cardinality $\}$. By the definition of clique neighborhood dominating set $\left\langle\mathrm{N}\left(\mathrm{D}_{\text {ncs }}(\mathrm{G})>\right.\right.$ is complete $\therefore \mathrm{V}-\mathrm{D}_{\text {ncs }}(\mathrm{G})=\left\{\mathrm{v}_{1}, \mathrm{v}_{2}, \ldots\right.$ $\left.\mathrm{v}_{\mathrm{i}-1}, \mathrm{v}_{\mathrm{i}+1}, \ldots \mathrm{v}_{\mathrm{n}}\right\}$ and $<\mathrm{V}-\mathrm{D}_{\mathrm{ncs}}(\mathrm{G})>$ is complete with all arcs as strong arcs.

\section{Theorem 4.6}

If $G$ is a strong complete fuzzy graph and $D_{\text {ncs }}(G)$ is the neighborhood clique dominating set of $G$ using strong arcs then fuzzy neighborhood clique dominating number of $G$ using strong arc is $\gamma_{\mathrm{ncs}}(G)=\min$ $\left\{\sigma\left(\mathrm{v}_{\mathrm{i}}\right) / \mathrm{v}_{\mathrm{i}} \in \mathrm{V}\right\}$

\section{Proof:}

Let $\mathrm{G}$ be a strong complete fuzzy graph with vertex set $\mathrm{V}=\left\{\mathrm{v}_{1}, \mathrm{v}_{2}, \ldots \mathrm{v}_{\mathrm{i}-1}, \mathrm{v}_{\mathrm{i}}, \mathrm{v}_{\mathrm{i}+1}, \ldots \mathrm{v}_{\mathrm{n}}\right\}$ having distinct fuzzy vertex cardinality. Let $D_{\text {ncs }}(G)$ be the fuzzy neighborhood clique dominating set of $G$ using strong arc . Then $D_{\text {ncs }}(G)=\left\{\mathrm{v}_{\mathrm{i}} / \mathrm{v}_{\mathrm{i}}\right.$ is the vertex of minimum fuzzy cardinality $\} . \therefore$ The fuzzy neighborhood clique dominating number of $G$ using strong $\operatorname{arc}$ is $\gamma_{\mathrm{ncs}}(\mathrm{G})=\min \left\{\sigma\left(\mathrm{v}_{\mathrm{i}}\right) / \mathrm{v}_{\mathrm{i}} \in \mathrm{V}\right\}$

\section{Theorem 4.7}

Let $G$ be a strong complete fuzzy graph and $D_{\text {gncs }}(G)$ is the global fuzzy neighborhood clique dominating set of $G$ using strong arc then $\gamma_{\mathrm{gncs}}(\mathrm{G})=\min \left\{\sigma\left(\mathrm{v}_{\mathrm{i}}\right) / \mathrm{v}_{\mathrm{i}} \in \mathrm{V}\right\}$.

\section{Proof :}

By the previous theorem, $\gamma_{\mathrm{ncs}}(\mathrm{G})=\min \left\{\sigma\left(\mathrm{v}_{\mathrm{i}}\right) / \mathrm{v}_{\mathrm{i}} \in \mathrm{V}\right\}$ and also $\gamma_{\mathrm{ncs}}(\bar{G}) \geq \gamma_{\mathrm{ncs}}(\mathrm{G})$.

$\therefore \gamma_{\text {gncs }}(\mathrm{G})=\gamma_{\mathrm{ncs}}(\mathrm{G})=\min \left\{\sigma\left(\mathrm{v}_{\mathrm{i}}\right) / \mathrm{v}_{\mathrm{i}} \in \mathrm{V}\right\}$.

\section{Theorem 4.8}

Let $\mathrm{G}$ be a strong complete fuzzy graph and $\mathrm{D}_{\text {ncs }}(\mathrm{G})$ be the fuzzy neighborhood clique dominating set of $\mathrm{G}$ using strong arc . Then $\gamma_{\mathrm{ncs}}(\mathrm{G}) \leq \gamma_{\mathrm{ncs}}\left(\mathrm{G}_{1}\right) \leq \gamma_{\mathrm{ncs}}\left(\mathrm{G}_{2}\right) \leq \gamma_{\mathrm{ncs}}\left(\mathrm{G}_{3}\right) \leq \ldots \leq \gamma_{\mathrm{ncs}}\left(\mathrm{G}_{\mathrm{n}-1}\right)$ where $\mathrm{G}_{\mathrm{i}}$ is a fuzzy graph with $\mathrm{V}_{\mathrm{i}}=\left\{\mathrm{V}-\left\{\mathrm{v}_{\mathrm{i}}\right\} / \sigma\left(\mathrm{v}_{\mathrm{i}}\right)=\right.$ minimum fuzzy vertex cardinality $\}$

\section{Proof:}

Let $\mathrm{G}$ be a strong complete fuzzy graph with vertex set $\mathrm{V}=\left\{\mathrm{v}_{1}, \mathrm{v}_{2}, \ldots \mathrm{v}_{\mathrm{i}-1}, \mathrm{v}_{\mathrm{i}}, \mathrm{v}_{\mathrm{i}+1}, \ldots \mathrm{v}_{\mathrm{n}}\right\}$. Let $\mathrm{G}_{\mathrm{i}}$ be the fuzzy graph induced by the vertex set $V_{i}=\left\{V-D_{\text {ncs }}(G)\right\}, D_{\text {ncs }}\left(G_{i}\right)$ is the neighborhood clique dominating set using strong arc with respect to $V_{i}$. By definition $\left\langle N\left(D_{\text {ncs }}\left(G_{i}\right)>\right.\right.$ is complete.

Clearly, the fuzzy neighborhood clique dominating number using strong arc $G_{i}$ 's are $\gamma_{\text {ncs }}(G), \gamma_{\text {ncs }}\left(G_{1}\right)$, $\gamma_{\mathrm{ncs}}\left(\mathrm{G}_{2}\right), \gamma_{\mathrm{ncs}}\left(\mathrm{G}_{3}\right), \ldots \ldots \gamma_{\mathrm{ncs}}\left(\mathrm{G}_{\mathrm{n}-1}\right)$ such that $\gamma_{\mathrm{ncs}}(\mathrm{G}) \leq \gamma_{\mathrm{ncs}}\left(\mathrm{G}_{1}\right) \leq \gamma_{\mathrm{ncs}}\left(\mathrm{G}_{2}\right) \leq \gamma_{\mathrm{ncs}}\left(\mathrm{G}_{3}\right) \ldots \ldots \ldots \leq \gamma_{\mathrm{ncs}}\left(\mathrm{G}_{\mathrm{n}-1}\right)$

\section{Theorem 4.9}

If $G$ is a fuzzy graph then $\gamma_{\mathrm{s}}(\mathrm{G}) \leq \gamma_{\mathrm{ncs}}(\mathrm{G})$.

\section{Proof:}

Let $G$ be a strong complete fuzzy graph . Let $D_{s}(G)$ and $D_{\text {ncs }}(G)$ be the dominating set and neighborhood dominating set of $G$ using strong arc. Since $D_{\text {ncs }}(G)$ is the neighborhood clique dominating set of $G$ using strong arc, $\mathrm{D}_{\text {ncs }}(\mathrm{G})$ is also a dominating set, but need not be minimum fuzzy dominating set. $\therefore$ $\gamma_{\mathrm{s}}(\mathrm{G}) \leq \gamma_{\mathrm{ncs}}(\mathrm{G})$. 


\section{Fuzzy Global Diminishing Dominatioon Number Using Strong Arc.}

\section{Definition 5.1}

Let $G$ be a fuzzy graph without isolated vertices.A subset $D_{\text {dds }}(G)$ of $V$ is said to be a Diminishing domination set of Gusing strong arcs if $D_{\text {dds }}(G)$ contains the vertices of degree less than the vertices of maximum degree in $\mathrm{G}$. $\mathrm{D}_{\mathrm{dds}}(\mathrm{G})=\left\{\mathrm{v}_{\mathrm{i}} / \mathrm{d}\left(\mathrm{v}_{\mathrm{i}}\right)<\Delta\right\}$. The fuzzy diminishing domination number $\gamma_{\mathrm{dds}}(\mathrm{G})$ of $\mathrm{G}$ using strong arc is the minimum fuzzy cardinality taken over all minimal diminishing dominating sets of $\mathrm{G}$.

Similarly $\mathrm{D}_{\mathrm{dds}}(\bar{G})$ is Diminishing domination set of $\bar{G}$ using strong arcs and $\gamma_{\mathrm{dds}}(\bar{G})$ is the Diminishing domination number of $\bar{G}$ using strong arc. Then the fuzzy global diminishing domination number of $\mathrm{G}$ is the minimum of $\gamma_{\mathrm{dds}}(\mathrm{G})$ and $\gamma_{\mathrm{dds}}(\bar{G}) \cdot \gamma_{\mathrm{gdds}}(\mathrm{G})=\min \left\{\gamma_{\mathrm{dds}}(\mathrm{G}), \gamma_{\mathrm{dds}}(\bar{G})\right\}$

\section{Example 5.2}

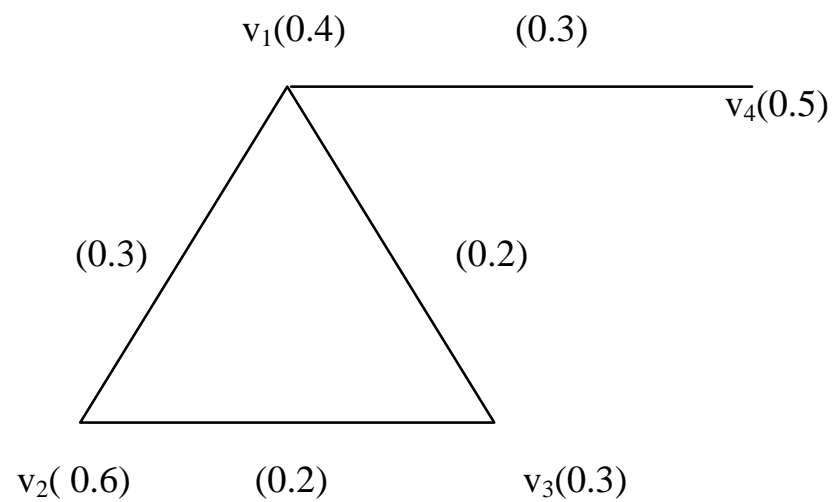

$$
\begin{aligned}
& D_{\text {dds }}(G)=\left\{\mathrm{v}_{3}, \mathrm{v}_{4}\right\} \\
& \gamma_{\mathrm{dds}}(\mathrm{G})=0.8
\end{aligned}
$$

(G) -Figure 2(a)

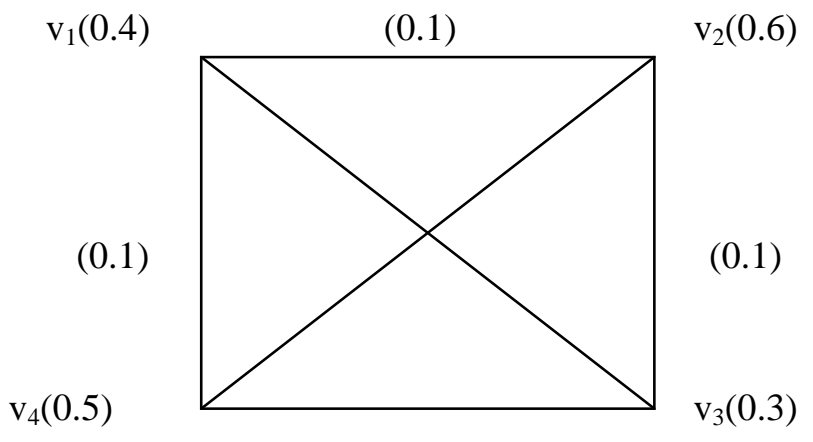

$$
\begin{aligned}
& \mu\left(\mathrm{v}_{2}, \mathrm{v}_{4}\right)=0.5 \\
& \mu\left(\mathrm{v}_{1}, \mathrm{v}_{3}\right)=0.1 \\
& \mathrm{D}_{\mathrm{dds}}(\bar{G})=\left\{\mathrm{v}_{1}\right\} \\
& \gamma_{\mathrm{dds}}(\bar{G})=0.4 \\
& \therefore \gamma_{\text {gdds }}(\mathrm{G})=0.4
\end{aligned}
$$

$(\bar{G})$-Figure 2(b) 


\section{Theorem 5.3}

If $G$ is a strong complete fuzzy graph with distinct vertex cardinality then $\gamma_{\text {gdds }}(G)=\min \left\{\sigma\left(v_{i}\right)\right\}$.

\section{Proof:}

Let $G$ be a strong complete fuzzy graph with distinct vertex cardinality and let $D_{\text {dds }}(G)$ be the diminishing dominating set of $\mathrm{G}$ using strong arcs which contains the vertices of degree less than $\Delta$. Clearly $\mathrm{D}_{\mathrm{dds}}(\mathrm{G})=\left\{\mathrm{v}_{\mathrm{i}} / \mathrm{v}_{\mathrm{i}} \in \mathrm{V}\right.$ is the minimum fuzzy vertex cardinality $\} . \therefore$ The fuzzy diminishing domination number of $\mathrm{G}$ using strong arcs is $\gamma_{\mathrm{dds}}(\mathrm{G})=\min \left\{\sigma\left(\mathrm{v}_{\mathrm{i}}\right) / \mathrm{v}_{\mathrm{i}} \in G\right\}$. Similarly the fuzzy diminishing domination number of $\bar{G}$ using strong $\operatorname{arcs}$ is $\gamma_{\mathrm{dds}}(\bar{G})=\min \left\{\sigma\left(\mathrm{v}_{\mathrm{i}}\right) / \mathrm{v}_{\mathrm{i}} \in \bar{G}\right\} \geq \gamma_{\mathrm{dds}}(\mathrm{G})$.

$\therefore \gamma_{\mathrm{gdds}}(\mathrm{G})=\min \left\{\gamma_{\mathrm{dds}}(\mathrm{G}), \gamma_{\mathrm{dds}}(\bar{G})\right\}=\gamma_{\mathrm{dds}}(\mathrm{G})=\min \left\{\sigma\left(\mathrm{v}_{\mathrm{i}}\right) / \mathrm{v}_{\mathrm{i}} \in G\right\}$.

\section{Corollary : $\mathbf{5 . 3 . 1}$}

If $\mathrm{G}$ is a regular fuzzy graph then $\gamma_{\mathrm{gdds}}(\mathrm{G})$ does not exist.

\section{Corollary: 5.3 .2}

If $\mathrm{G}$ is a totally regular fuzzy graph then $\gamma_{\mathrm{gdds}}(\mathrm{G})$ does not exist.

\section{Corollary: 5.3 .3}

If $\mathrm{G}$ is a strong complete fuzzy graph then $\mathrm{n}\left[\mathrm{D}_{\text {gdds }}(\mathrm{G})\right]=1$.

\section{Theorem 5.4}

If $\mathrm{G}$ is a fuzzy graph then (i) $\gamma_{\mathrm{gdds}}(\mathrm{G}) \leq \mathrm{p}-\Delta$, where $\mathrm{p}=\sum \sigma(\mathrm{u})$ and (ii) $\delta \leq \gamma_{\mathrm{gdds}}(\mathrm{G})$.

\section{Proof:}

Let $\mathrm{G}$ be a fuzzy graph and $\mathrm{D}_{\mathrm{dds}}(\mathrm{G})$ be the fuzzy diminishing dominating set of $\mathrm{G}$ using strong arcs which contains the vertices of degree less than $\Delta$. Clearly $\gamma_{\mathrm{gdds}}(\mathrm{G})+\Delta \leq \sum \sigma\left(\mathrm{u}_{\mathrm{i}}\right)=\mathrm{p} . \therefore \gamma_{\mathrm{gdds}}(\mathrm{G}) \leq \mathrm{p}-\Delta$ and $\gamma_{\text {gdds }}(\mathrm{G}) \geq \delta$.

\section{Fuzzy Global Regular Domination Number Using Strong Arc.}

\section{Definition 6.1}

The domination set $D_{r s}(G)$ of the fuzzy graph $G$ is said to be regular dominating set using strong arc if every vertex in $D_{r s}(G)$ is of same degree. The fuzzy regular domination number $\gamma_{r s}(G)$ is the minimum fuzzy cardinality taken over all minimal regular dominating sets of $\mathrm{G}$.

Similarly $\mathrm{D}_{\mathrm{rs}}(\bar{G})$ is the fuzzy regular dominating set of $\bar{G}$ and $\gamma_{\mathrm{rs}}(\bar{G})$ is the minimum fuzzy cardinality taken over all minimal regular dominating sets of $\bar{G}$.

Fuzzy global regular domination number using strong arc $\gamma_{\mathrm{grs}}(\mathrm{G})$ is the minimum of $\gamma_{\mathrm{rs}}(\mathrm{G})$ and $\gamma_{\mathrm{rs}}(\bar{G})$. $\therefore$ $\gamma_{\mathrm{grs}}(\mathrm{G})=\min \left\{\gamma_{\mathrm{rs}}(\mathrm{G}), \gamma_{\mathrm{rs}}(\bar{G})\right\}$ and the corresponding set $\mathrm{D}_{\mathrm{grs}}(\mathrm{G})$ of $\gamma_{\mathrm{grs}}(\mathrm{G})$ is said to be Global regular dominating set using strong arc.

\section{Example 6.2}



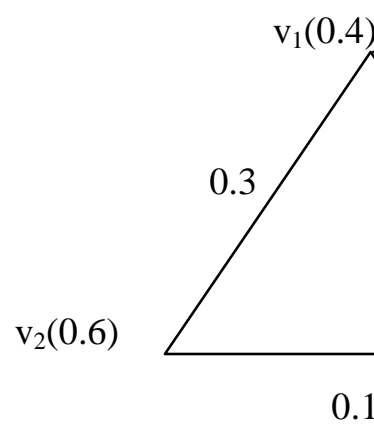

0.1

$\mathrm{v}_{4}(0.5)$

$$
\begin{aligned}
& D_{\mathrm{rs}}(\mathrm{G})=\left\{\mathrm{v}_{3}, \mathrm{v}_{4}\right\} \\
& \gamma_{\mathrm{rs}}(\mathrm{G})=0.8
\end{aligned}
$$

$\mathrm{v}_{3}(0.3)$

(G) - Figure 3(a)

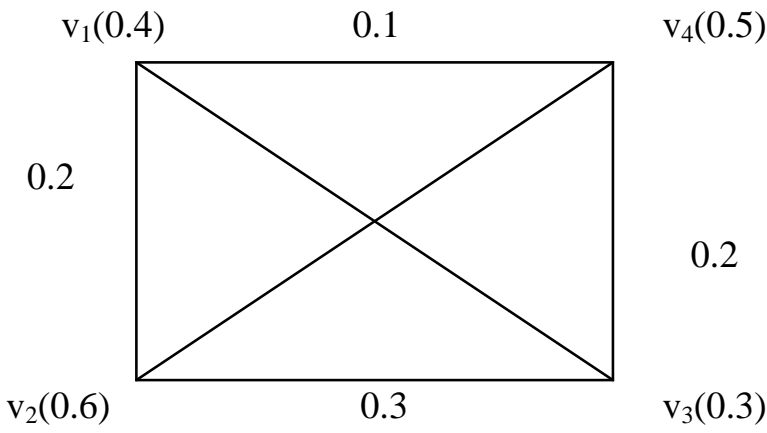

$(\bar{G})$-Figure 3(b)

\section{Theorem 6.3}

Let $\mathrm{G}$ be a k- regular fuzzy graph and c- totally regular fuzzy graph with strong arcs. Then $\gamma_{\mathrm{grs}}(\mathrm{G})<\mathrm{n}(\mathrm{c}-\mathrm{k}), \mathrm{n}$ is the number of fuzzy vertices.

\section{Proof:}

Let $\mathrm{G}$ be a k- regular fuzzy graph and c- totally regular fuzzy graph with strong arcs.

$\therefore \mathrm{d}\left(\mathrm{v}_{\mathrm{i}}\right)=\mathrm{k}, \forall \mathrm{v}_{\mathrm{i}} \in \mathrm{V}$ and $\mathrm{d}_{\mathrm{t}}\left(\mathrm{v}_{\mathrm{i}}\right)=\mathrm{d}\left(\mathrm{v}_{\mathrm{i}}\right)+\sigma\left(\mathrm{v}_{\mathrm{i}}\right)=\mathrm{c}$.

$\mathrm{d}\left(\mathrm{v}_{\mathrm{i}}\right)=\mathrm{k} . \therefore \sum \mathrm{d}\left(\mathrm{v}_{\mathrm{i}}\right)=\sum \mathrm{k}=\mathrm{nk}$

$\sum \mathrm{d}_{\mathrm{t}}\left(\mathrm{v}_{\mathrm{i}}\right)=\sum\left[\mathrm{d}\left(\mathrm{v}_{\mathrm{i}}\right)+\sigma\left(\mathrm{v}_{\mathrm{i}}\right)\right]$

$\mathrm{nc}=\mathrm{nk}+\sum \sigma\left(\mathrm{v}_{\mathrm{i}}\right) . \quad \therefore \sum \sigma\left(\mathrm{v}_{\mathrm{i}}\right)=\mathrm{n}(\mathrm{c}-\mathrm{k})$.

$\mathrm{p}=\sum \sigma\left(\mathrm{v}_{\mathrm{i}}\right)=\mathrm{n}(\mathrm{c}-\mathrm{k})$. By definition $\gamma_{\mathrm{grs}}(\mathrm{G})<\sum \sigma\left(\mathrm{v}_{\mathrm{i}}\right) . \therefore \gamma_{\mathrm{grs}}(\mathrm{G})<\mathrm{n}(\mathrm{c}-\mathrm{k})$. 


\section{Theorem 6.4}

If $\mathrm{G}$ is a strong complete fuzzy graph with equal fuzzy cardinality, then $\gamma_{\mathrm{grs}}(\mathrm{G})$ exists.

\section{Proof:}

Let $G$ be a strong complete fuzzy graph with equal fuzzy cardinality. Then $\gamma_{\mathrm{rs}}(\mathrm{G})$ exists, since each vertex $\mathrm{v}_{\mathrm{i}}$ dominates the remaining vertices. Similarly $\gamma_{\mathrm{rs}}(\bar{G})$ also exists. Therefore $\gamma_{\mathrm{grs}}(\mathrm{G})$ exists.

\section{Corollary 6.5}

If $G$ is a regular fuzzy graph with strong arcs, then $\gamma_{\mathrm{grs}}(\mathrm{G})$ exists.

\section{Theorem 6.6}

If $\mathrm{G}$ is a strong complete bipartite fuzzy graph $\mathrm{K}_{\mathrm{m}, \mathrm{m}}$ with $\sigma\left(\mathrm{v}_{\mathrm{i}}\right)=\mathrm{c}, \forall \mathrm{v}_{\mathrm{i}} \in \mathrm{V}$, then $\gamma_{\mathrm{rs}}(\mathrm{G})$ exists and $\gamma_{\mathrm{rs}}(\mathrm{G})=2 \mathrm{c}$.

Proof:

Let $\mathrm{G}=\mathrm{K}_{\mathrm{m}, \mathrm{m}}$ be a complete bipartite fuzzy graph with all arcs as strong $\operatorname{arcs}$ and $\sigma\left(\mathrm{v}_{\mathrm{i}}\right)=\mathrm{c}, \forall \mathrm{v}_{\mathrm{i}} \in \mathrm{V}$. Then by definition of complete bipartite fuzzy graph, $\mathrm{n}\left[\mathrm{D}_{\mathrm{rs}}(\mathrm{G})\right]=2$. Therefore $\gamma_{\mathrm{rs}}(\mathrm{G})=2 \mathrm{c}$.

\section{Result 6.7}

If $\mathrm{G}=\mathrm{FP}_{\mathrm{n}}$ is a fuzzy path with equal fuzzy vertex cardinality and having all edges as effective edges then fuzzy regular domination number exists for $\mathrm{n}>3$.

\section{Fuzzy Global Regular Split Domination Number Using Strong Arc.}

\section{Definition 7.1}

The dominating set $D_{\text {rss }}(G)$ of the fuzzy graph $G$ is said to be regular split dominating set using strong arc if (i) every vertex in $D_{\text {rss }}(G)$ is of same degree. (ii) $\left\langle V-D_{\text {rss }}(G)>\right.$ is disconnected. The fuzzy regular split domination number using strong arc $\gamma_{\mathrm{rss}}(\mathrm{G})$ is the minimum fuzzy cardinality taken over all minimal regular split dominating sets of $\mathrm{G}$ using strong arc.

Similarly $\gamma_{\mathrm{rss}}(\bar{G})$ is the minimum fuzzy cardinality taken over all minimal regular split dominating sets of $\bar{G}$ using strong arc. Then fuzzy global regular split domination number $\gamma_{\text {grss }}(G)$ using strong arc is minimum of $\gamma_{\mathrm{rss}}(\mathrm{G}), \gamma_{\mathrm{rss}}(\bar{G})$. (ie) $\gamma_{\mathrm{grss}}(\mathrm{G})=\min \left\{\gamma_{\mathrm{rss}}(\mathrm{G}), \gamma_{\mathrm{rss}}(\bar{G})\right\}$.

\section{Example 7.2}




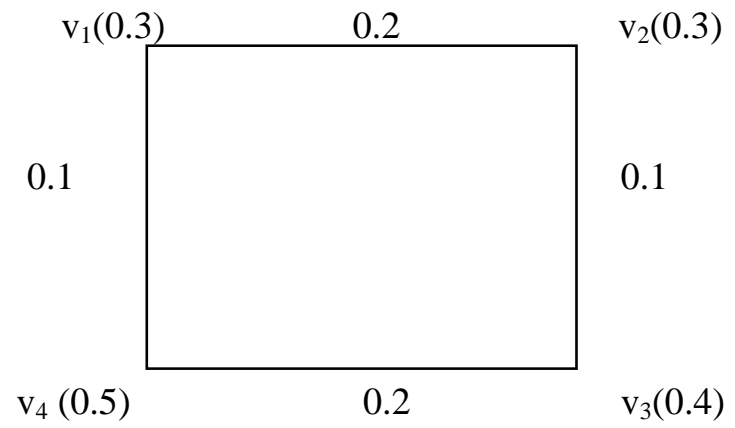

$$
\begin{aligned}
D_{\mathrm{rss}}(\mathrm{G}) & =\left\{\mathrm{v}_{1}, \mathrm{v}_{3}\right\} \\
\gamma_{\mathrm{rss}}(\mathrm{G}) & =0.7
\end{aligned}
$$

(G) - Figure 4(a)

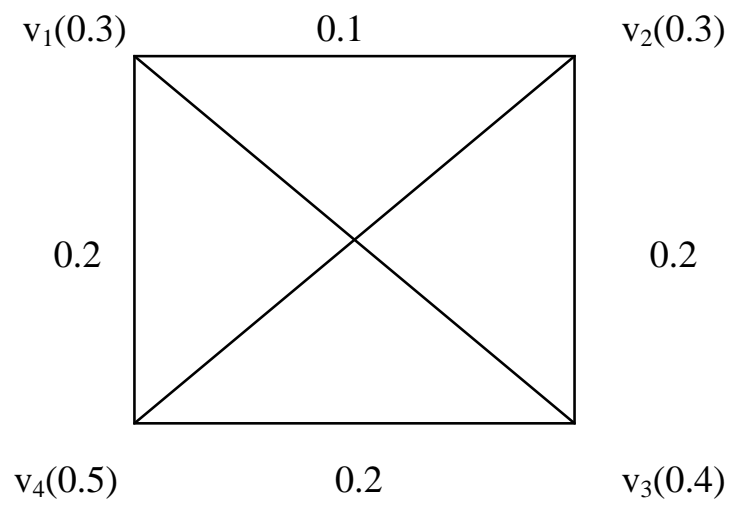

$$
\begin{aligned}
& \mu\left(\mathrm{v}_{1}, \mathrm{v}_{3}\right)=0.3 \\
& \mu\left(\mathrm{v}_{2}, \mathrm{v}_{4}\right)=0.3
\end{aligned}
$$

$(\bar{G})$-Figure 4(b)

For $(\bar{G})$, regular split domination number does not exist.

\section{Result 7.3}

Let $\mathrm{G}$ be a fuzzy path with equal fuzzy cardinality and having all edges as effective edges. Then $\gamma_{\mathrm{grss}}(\mathrm{G})$ exists for $\mathrm{FP}_{3}, \mathrm{FP}_{4}, \mathrm{FP}_{5}$ only. For $\mathrm{FP}_{\mathrm{n}}, \mathrm{n}>5$, global regular split domination number does not exist.

\section{Result 7.4}

Global regular split domination using strong arc does not exist for fuzzy paths with distinct fuzzy vertex cardinality.

\section{Theorem 7.5}

Regular split domination number using strong arc exists for fuzzy paths and fuzzy cycles ( For $\mathrm{FC}_{\mathrm{n}, \mathrm{n}}>3$ ). But global regular split domination number using strong arc does not exist for fuzzy paths and fuzzy cycles. 


\section{Proof:}

Let $\mathrm{G}$ be a fuzzy path or fuzzy cycle. If $\mathrm{D}_{\mathrm{rss}}(\mathrm{G})$ is a regular split domination set of $\mathrm{G}$. Then by definition of $\bar{G}$, regular dominating set of $\bar{G}, \mathrm{D}_{\mathrm{rs}}(\bar{G})$ can be found out, but $<\mathrm{V}-\mathrm{D}_{\mathrm{rs}}(\bar{G})>$ is not disconnected. $\therefore$ Regular split domination number using strong arc does not exist for $\overline{F P}_{\mathrm{n}}$ or $\overline{F C}_{\mathrm{n}} \therefore$ Global regular split domination number does not exist for $\mathrm{FP}_{\mathrm{n}}$ or $\mathrm{FC}_{\mathrm{n}}$.

\section{Fuzzy Global Regular Non split Domination Number Using Strong Arc.}

\section{Definition 8.1}

The dominating set $D_{\text {rnss }}(G)$ of the fuzzy graph $G$ is said to be regular split dominating set using strong arc if (i) every vertex in $\mathrm{D}_{\text {rnss }}(\mathrm{G})$ is of same degree. (ii) $<\mathrm{V}-\mathrm{Dn}_{\mathrm{rss}}(\mathrm{G})>$ is connected. The fuzzy regular non split domination number using strong arc $\gamma_{\text {rnss }}(G)$ is the minimum fuzzy cardinality taken over all minimal regular non split dominating sets of $\mathrm{G}$ using strong arc.

Similarly $\gamma_{\mathrm{rnss}}(\bar{G})$ is the minimum fuzzy cardinality taken over all minimal regular non split dominating sets of $\bar{G}$ using strong arc. Then fuzzy global regular non split domination number $\gamma_{\text {grnss }}(\mathrm{G})$ using strong arc is minimum of $\gamma_{\mathrm{rnss}}(\mathrm{G}), \gamma_{\mathrm{rnss}}(\bar{G})$. (ie) $\gamma_{\mathrm{grnss}}(\mathrm{G})=\min \left\{\gamma_{\mathrm{rnss}}(\mathrm{G}), \gamma_{\mathrm{rnss}}(\bar{G})\right\}$.

\section{Example 8.2}

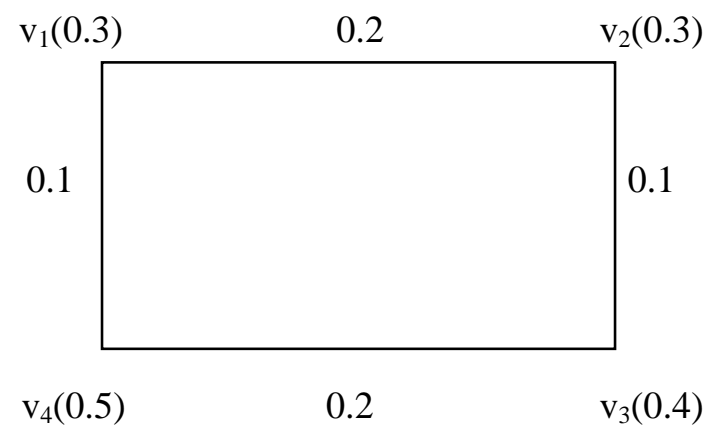

$$
\mathrm{D}_{\text {rnss }}(\mathrm{G})=\left\{\mathrm{v}_{1}, \mathrm{~V}_{2}\right\}
$$$$
\gamma_{\mathrm{rnss}}(\mathrm{G})=0.6
$$

(G) - Figure 5(a)

0.1

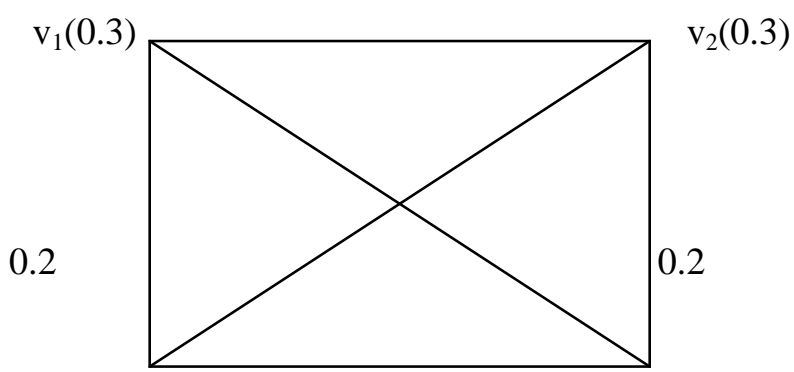

$$
\begin{aligned}
& \mu\left(\mathrm{v}_{1}, \mathrm{v}_{3}\right)=0.3 \\
& \mu\left(\mathrm{v}_{2}, \mathrm{v}_{4}\right)=0.3 \\
& \mathrm{D}_{\text {rnss }}(\bar{G})=\left\{\mathrm{v}_{1}\right\} \\
& \gamma_{\text {rnss }}(\bar{G})=0.3 \\
& \therefore \gamma_{\text {grnss }}(\mathrm{G})=0.3
\end{aligned}
$$
$\mathrm{v}_{4}(0.5)$
0.2
$\mathrm{v}_{3}(0.4)$ 


\section{$(\bar{G})$ - Figure 5(b)}

\section{Theorem 8.3}

Fuzzy global regular non split domination number using strong arc exist for strong complete graphs $\left(\mathrm{K}_{\mathrm{n}}\right)$

Proof:

Let $\mathrm{G}=\mathrm{K}_{\mathrm{n}}$ be a strong complete fuzzy graph. Since every vertex of $\mathrm{G}$ is adjacent to every other vertex, it is possible to find a regular dominating set $\mathrm{D}$ of $\mathrm{G}$ such that $\langle\mathrm{V}-\mathrm{D}(\mathrm{G})\rangle$ is connected. (ie) Fuzzy regular non split domination number exist for G. Similarly regular non split dominating set exist for $\bar{G}$. F Fuzzy global regular non split domination number exist for $G=K_{n}$.

\section{Fuzzy Global Connected Domination Number Using Strong Arc.}

\section{Definition 9.1}

The dominating set $D_{c s}(G)$ of a fuzzy connected graph $G$ is said to be a connected dominating set using strong arc if $\left\langle D_{c s}\left(G>\right.\right.$ is connected. The fuzzy connected domination number using strong arc $\gamma_{c s}(G)$ is the minimum cardinality taken over all minimal connected domination sets of $\mathrm{G}$.

Similarly $\gamma_{\mathrm{cs}}(\bar{G})$ is the fuzzy connected domination number using strong arc of $\bar{G}$. Then fuzzy global connected domination number of a connected fuzzy graph $G \gamma_{\mathrm{gcs}}(\mathrm{G})$ is the minimum of $\gamma_{\mathrm{cs}}(\mathrm{G})$ and $\gamma_{\mathrm{cs}}(\bar{G})$. (ie) $\gamma_{\mathrm{gcs}}(\mathrm{G})=\min \left\{\gamma_{\mathrm{cs}}(\mathrm{G}), \gamma_{\mathrm{cs}}(\bar{G})\right\}$

\section{Example 9.2}

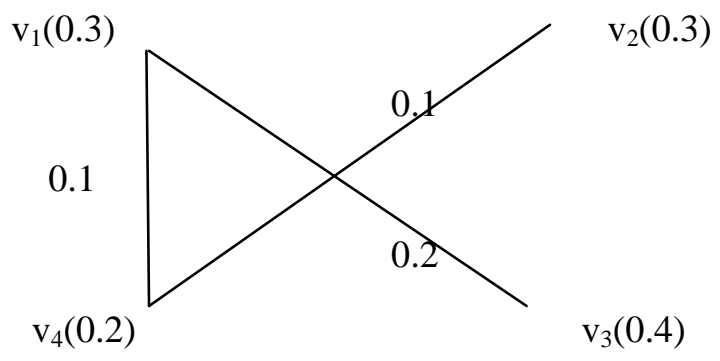

$$
\begin{aligned}
& D_{c s}(G)=\left\{v_{1}, v_{4}\right\} \\
& \gamma_{c s}(G)=0.5
\end{aligned}
$$

(G) - Figure 6(a) 


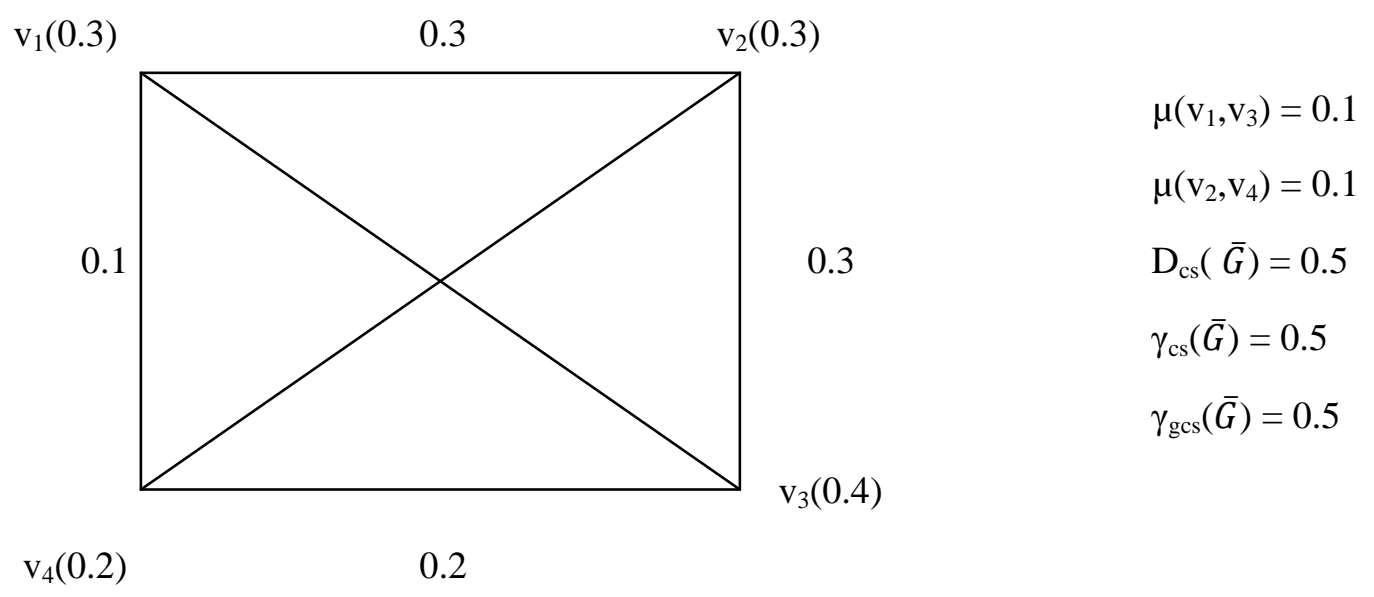

\section{$(\bar{G})$ - Figure 6(b)}

\section{Remark :}

If $D_{\text {gcs }}(G)$ is a global connected dominating set of $G$ using strong arcs, then $<V-D_{\text {gcs }}(G)>$ need not be connected.

\section{Example 9.3}

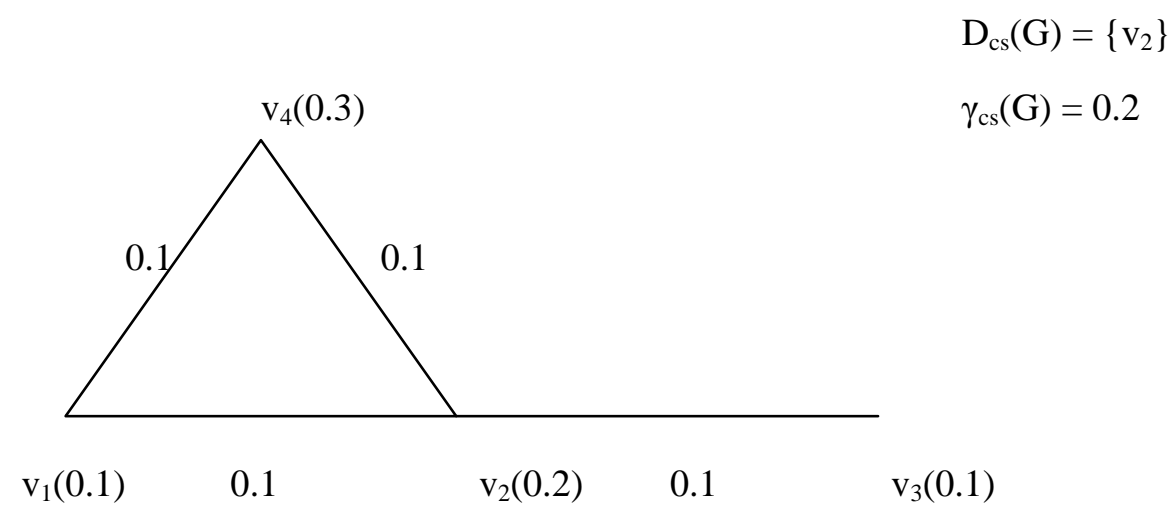

(G) - Figure 7(a) 


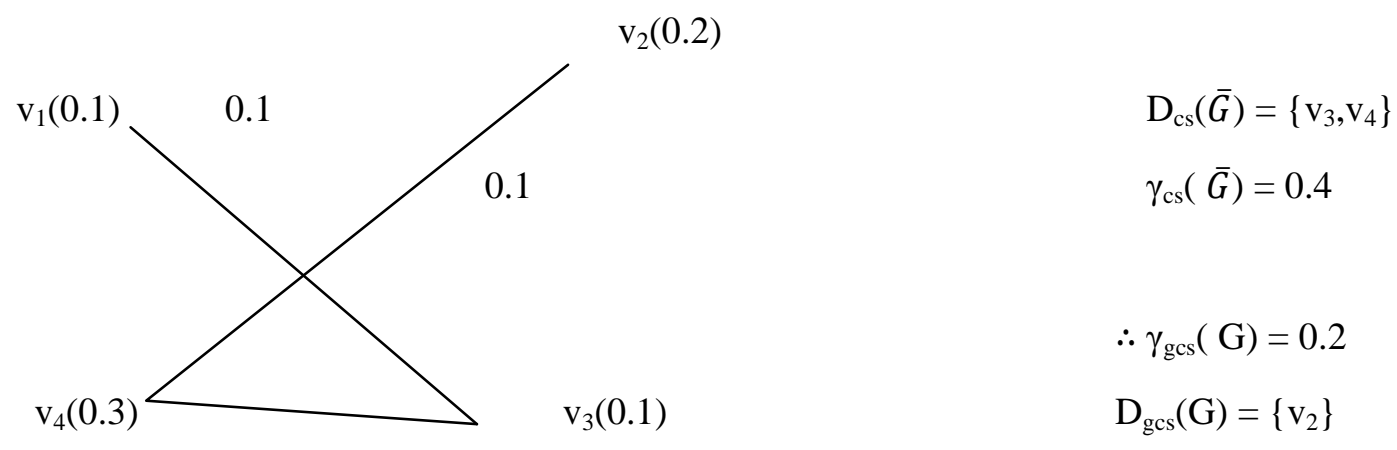

0.1

$(\bar{G})$ - Figure 7(b)

\section{Theorem : 9.4}

For any connected fuzzy graph $\mathrm{G} \gamma_{\mathrm{gcs}}(\mathrm{G}) \leq \gamma_{\mathrm{cs}}(\mathrm{G})$

\section{Proof :}

By definition, global connected domination number using strong arc is the minimum of $\gamma_{\mathrm{cs}}(\mathrm{G})$ and $\gamma_{\mathrm{cs}}(\bar{G}) \therefore \gamma_{\mathrm{gcs}}(\mathrm{G}) \leq \gamma_{\mathrm{cs}}(\mathrm{G})$.

\section{Fuzzy Global Connected Split Domination Number Using Strong Arc.}

\section{Definition 10.1}

The dominating set $D_{\text {css }}(G)$ of a fuzzy connected graph $G$ is said to be a fuzzy connected split dominating set using strong arc if $<\mathrm{D}_{\text {css }}(\mathrm{G}>$ is connected. The fuzzy connected domination number using strong arc $\gamma_{\mathrm{css}}(\mathrm{G})$ is the minimum cardinality taken over all minimal connected split domination sets of $\mathrm{G}$.

Similarly $\gamma_{\text {css }}(\bar{G})$ is the fuzzy connected split domination number using strong arc of $\bar{G}$. Then fuzzy global connected split domination number $\gamma_{\mathrm{gcss}}(\mathrm{G})$ of a connected fuzzy graph $\mathrm{G}$ is the minimum of $\gamma_{\mathrm{css}}(\mathrm{G})$ and $\gamma_{\text {css }}(\bar{G})$. (ie) $\gamma_{\mathrm{gcss}}(\mathrm{G})=\min \left\{\gamma_{\mathrm{css}}(\mathrm{G}), \gamma_{\mathrm{css}}(\bar{G})\right\}$. 


\section{Example 10.2}

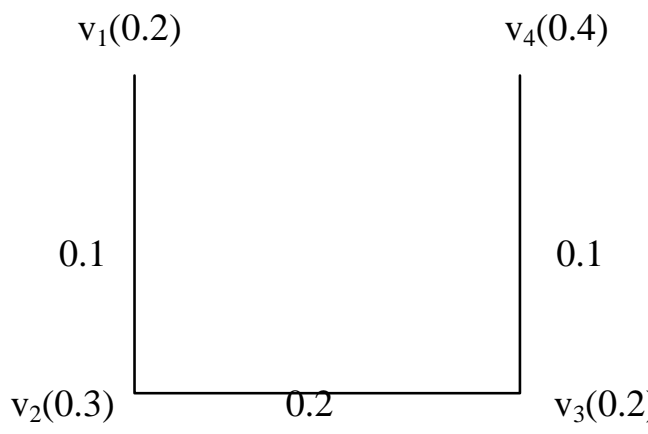

$$
\begin{aligned}
& D_{\text {css }}(G)=\left\{\mathrm{v}_{2}, \mathrm{v}_{3}\right\} \\
& \gamma_{\mathrm{css}}(\mathrm{G})=0.5
\end{aligned}
$$

\section{(G) - Figure 8(a)}

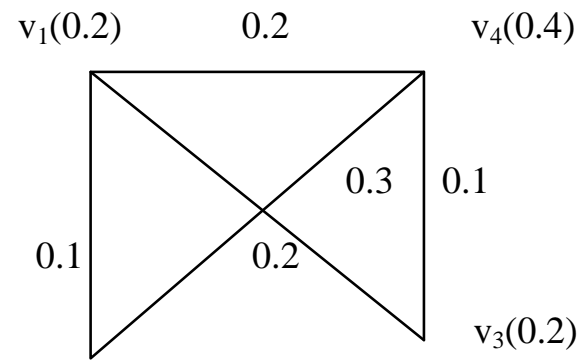

$$
\begin{aligned}
& \mathrm{D}_{\mathrm{css}}(\bar{G})=\left\{\mathrm{v}_{1}, \mathrm{v}_{4}\right\} \\
& \gamma_{\mathrm{css}}(\bar{G})=0.6 \\
& \gamma_{\mathrm{gcss}}(\mathrm{G})=0.5
\end{aligned}
$$

$\mathrm{v}_{2}(0.3)$

\section{$(\bar{G})$ - Figure 8(b)}

\section{Acknowledgment}

Thanks are due to the referees for their valuable comments and suggestions.

\section{REFERENCES}

[1] V.Senthil Kumar, C.Y.Ponnappan, A.Selvam, “A Note on Domination in Fuzzy Graph Using Strong Arc”, Journal of Applied Science and Computations, vol 5, issue 6,(June 2018),pp. 84-92

[2] C.Y.Ponnappan, R.Muthuraj,S.Basheer Ahamed, “ New Domination Parameters in Fuzzy Graphs”, International Journal of Mathematics and Technology (IJMTT), vol 36, no.2, (August 2016), pp 99-102

[3] C.Y.Ponnappan, S.Basheer Ahamed, P.Surulinathan, “Connected Edge Domination in Fuzzy Graphs”, International Journal of Mathematics and its Applications, vol 3, Issue 2, (2015), pp. 133-137.

[4] C.Y.Ponnappan, S.Basheer Ahamed, P.Surulinathan, “Edge Domination in Fuzzy Graphs- New Approach", International Journal of IT , Engineering and Applied Sciences \& Research, vol 4, no. 1, (January 2015), pp 14-17

[5] C.Y.Ponnappan, S.Basheer Ahamed, P.Surulinathan, “ Inverse Edge Domination in Fuzzy Graphs", International Journal of Mathematics Trends and Tech, vol 20, no. 2, (April 2015) 
[6] E.Sampathkumar, H.B.Walikar (1979)."The connected domination number of a graph", Jour. Math Phy. Sci., 13 (6),(1979),pp. 607-613

[7] Sunitha M.S., Mathew S.,"Fuzzy Graph Theory: A survey”, Annals of Pure and Applied Mathematics, vol 4, (1), (2013),pp. 92-110

[8] Rosenfeld, A ., 1975. Fuzzy graphs. In : Zadeh, L.A ., Fu, K. S., Shimura , M. _ Eds ., Fuzzy Sets and Their Applicatoins. Academic Press, New York.

[9] Somasundaram , A., Somasundaram , S.,.”Domination in fuzzy graph - 1”, pattern recognition letter, 19 (9),(1998), pp.787791. 